\title{
ESTRATÉGIA DE MANUTENCÃO E AUMENTO DA DISPONIBILIDADE DE UM POSTO DE COMPRESSÃO DE GASES NA INDÚSTRIA PETROLÍFERA
}

\section{MAINTENANCE STRATEGY AND AVAILABITY INCREASING OF A GAS COMPRESSION STATION IN THE OIL INDUSTRY}

\author{
Nilis Adriano dos Santos* E-mail: nilsadrian@yahoo.com.br \\ Miguel Afonso Sellitto* E-mail: sellitto@unisinos.br \\ *Universidade do Vale do Rio dos Sinos (UNISINOS), São Leopoldo, RS
}

\begin{abstract}
Resumo: O objetivo deste artigo foi propor uma estratégia de manutenção e um conjunto de melhorias para aumento da disponibilidade em um posto de compressão de gases residuais do processo de destilação do petróleo, composto por dois compressores alternativos A e B em uma refinaria da indústria petrolífera. $O$ método de pesquisa foi a modelagem quantitativa. A metodologia incluiu o cálculo da atual disponibilidade e a sugestão de ações para elevá-la. Foram modelados os tempos até o reparo (TTR) e até a falha (TBF) dos compressores individuais e do posto de compressão de gases como um todo. Com os valores médios dos modelos (MTBF e MTTR) foram calculadas as disponibilidades individuais de $\mathrm{A}$ e $\mathrm{B}(32,4 \%$ e $83,3 \%$, respectivamente) e do conjunto, $96,7 \%$. Os dados foram coletados do sistema de informações da empresa. Pelos fatores de forma das distribuições associadas aos TBF, foi possível afirmar que, apesar de operarem há mais de vinte anos, ambas as máquinas se encontram na fase de mortalidade infantil. Tal fato se deve à troca de matéria-prima ocorrida há cerca de cinco anos: a planta passou a processar óleo mais pesado, originado do pré-sal, para o qual a instalação não foi projetada. Tal divergência pode ser caracterizada como falta de projeto, o que remete à estratégia de manutenção corretiva. Por fim, uma lista de melhorias corretivas de projeto foi apresentada para aumentar a disponibilidade do posto e encerrar a fase de falhas prematuras.
\end{abstract}

Palavras-chave: RCM. Confiabilidade. Mantenabilidade. Análise de Weibull. Manutenção. Compressor Alternativo.

\begin{abstract}
The purpose of this article was to propose a maintenance strategy and a set of improvement actions for increasing the availability in a compression station of waste gases from the petroleum distillation process, composed of two alternative compressors $A$ and $B$ in a plant of the oil industry. The research method was the quantitative modeling. The methodology includes the calculation of the current availability and suggesting actions to raise it. Time to repair (TTR) and time between failures (TBF) were modeled for the individual compressors and for the gas compression station as a whole. With the average values of the models (MTBF and MTTR) were calculated individual availabilities of $A$ and $B(32.4 \%$ and $83.3 \%$, respectively) and global, $96.7 \%$. The data were collected from the company's information system. By the form factors associated with TBF, it was possible to affirm that, despite operating for over twenty years, both machines are in the premature failures phase. This fact is due to the exchange of raw materials, which occurred about five years ago: the plant proceeded to process heavier oil, originated from the pre-salt layer, for which the installation was not designed. Such divergence may be characterized as a design fault, associated with the corrective maintenance strategy. Finally, a list of improvements projects was presented to increase the availability of the post and terminate the phase of premature failures.
\end{abstract}

Keywords: RCM. Reliability. Maintainability. Weibull Analysis. Gamma Analysis. Maintenance. Reciprocating Compressor. 


\section{INTRODUÇÃO}

A missão da manutenção industrial é garantir a disponibilidade de equipamentos e instalações, atendendo as necessidades do processo produtivo e a preservação do meio ambiente, com confiabilidade, segurança e custos aceitáveis (FURMANN, 2002). Na indústra, a função manutenção tem sido considerada fator importante na construção da vantagem competitiva. Segundo Slack et al. (2002), é pela função manutenção que as empresas gerenciam instalações físicas, prevenindo e corrigindo falhas e contribuindo para a otimização da produção.

Para Raposo (2011), tem aumentado a complexidade de equipamentos e operações industriais, dado o acúmulo de novas exigências e funcionalidades, que requerem técnicas mais avançadas de engenharia de manutenção, de modo a garantir custos, riscos e desempenho aceitáveis (SALGADO, 2008).

Em empresas de processamento contínuo, tais como plantas petroquímicas e refinarias de petróleo, a produção ocorre em bateladas de longa duração e grande volume, propiciando o surgimento de gargalos. Falhas em gargalos causam danos mais do que proporcionais à produtividade da instalação (SELLITTO, 2002). Neste cenário, segundo Tavares (1996), paradas ou perdas de capacidade de equipamentos podem significar perdas importantes e de difícil recuperação. As atuais plantas de processamento contínuo exigem expressivo número de equipamentos automatizados, tornando os processos mais complexos e exigindo mais articulação entre a estratégia de manutenção e a de produção (RAMOS FILHO et al., 2010).

Perdas em processos de produção e os respectivos custos envolvidos podem estar relacionadas à falta de planejamento e à deficiência na execução da estratégia de manutenção industrial (MARCORIM e LIMA, 2013). A confiabilidade do processo produtivo e a existência das condições necessárias para o cumprimento do Plano Mestre de Produção estão diretamente ligadas à eficácia do planejamento e da execução da manutenção. Portanto, para garantir rentabilidade em operações fabris, muitas vezes as empresas devem antes garantir confiabilidade e disponibilidade de seus equipamentos. Para tanto, devem desenvolver processos adequados de gestão da manutenção (TSANG, 2002; RAPOSO, 2011).

Para uma gestão eficaz da manutenção, é necessário enfoque sistêmico, que considere as diversas interfaces envolvidas, tais como os sistemas de recursos 
humanos, de produção, de materiais sobressalentes, e de execução da manutenção, o que deve incluir ao menos um histórico técnico e de custos de intervenção (SIMÕES et al., 2011). Para definir a estratégia de manutenção, uma importante base de apoio são métodos quantitativos já propostos na literatura. Sellitto (2007) aponta a RCM (Reliability-Centered Maintenance - Manutenção Centrada Na Confiabilidade) como um método que pode contribuir para o aumento da confiabilidade e da disponibilidade de equipamentos. A RCM ou MCC é uma metodologia estruturada de planejamento da manutenção que tem como objetivo garantir que os equipamentos atendam as funções desejadas pelos seus usuários dentro dos padrões de desempenho pretendidos, desde que seja formulada uma politica de manutenção adequada (FLEMING, 2000). A escolha desta política e o acompanhamento da sua aplicação podem garantir a funcionalidade dos equipamentos com confiabilidade e disponibilidade com segurança e a um custo adequado (BARROS e LIMA, 2011).

A literatura sobre manutenção industrial tem apresentado técnicas quantitativas aplicadas na definição das estratégias de manutenção, de modo similar ao que foi feito neste artigo. Alguns exemplos podem ser citados. Guzzon (2009) calculou o nível de confiabilidade global dos sistemas de propulsão de um sistema automatizado para transporte de pessoas. Wuttke e Sellitto (2008) calcularam a disponibilidade de uma válvula de processo petroquímico. Sellitto (2005) utilizou a modelagem de tempos entre falhas dos sistemas de uma linha de montagem de componentes para calcular a confiabilidade sistêmica da operação. Brand (2011) calculou a confiabilidade de uma linha de produção da indústria metal-mecânica e definiu estratégias de manutenção para os equipamentos da linha. Sellitto et al. (2002) sugeriram um método de gerenciamento de risco para operações de transporte coletivo por modelagem de tempos entre falhas de embreagens. Mendes (2011) utilizou simulação de Monte Carlo e análise de sensibilidade para construir planos de manutenção. Mengue e Sellitto (2013) definiram a estratégia de manutenção de uma planta petrolífera. Backlund e Akersten (2003) combinaram técnicas de gerenciamento de riscos e de confiabilidade para dar suporte tecnológico às decisões de manutenção.

O objetivo deste artigo é propor uma estratégia de manutenção e um conjunto de melhorias para aumento da disponibilidade em um posto de compressão de gases residuais do processo de destilação do petróleo, composto por dois 
compressores alternativos $\mathrm{A}$ e $\mathrm{B}$ em uma refinaria da indústria petrolífera. Os compressores trabalham em regime de revezamento, com a função de remover os vapores remanescentes do processo de destilação do petróleo e encaminhá-los para queima em turbogerador de energia elétrica. $O$ método de pesquisa é a modelagem quantitativa. A questão de pesquisa é: como aumentar a disponibilidade do posto de compressão? Este aumento é necessário, dadas as novas exigências de produtividade da instalação que surgiram há cerca de cinco anos, quando a planta começou a processar óleo oriundo da camada de pré-sal, diferente do óleo até então processado.

O restante do artigo está organizado em: revisão bibliográfica; pesquisa; discussão; proposição de alterações nas máquinas; e conclusão.

\section{CONFIABILIDADE, MANUTENIBILIDADE, DISPONIBILIDADE EM MANUTENÇÃO}

A confiabilidade em manutenção tem sua origem na década de 1950 na indústria aeronáutica americana. Em 1960, foi criado um grupo para o aperfeiçoamento de um programa específico de confiabilidade dentro da Federal Aviation Administration - FAA (KARDEC e NASCIF, 2001). A conformidade técnica e a qualidade dos projetos dos produtos não são os únicos parâmetros envolvidos. Percepções de clientes ao longo do tempo também contam (BORCHARDT et al., 2008). Portanto, a confiabilidade é um ciclo que se inicia nas fases de pesquisa, projeto e fabricação e é consolidada durante o uso do produto pelo cliente (FRITSCH e RIBEIRO, 1998).

Análises de confiabilidade usam dados quantitativos e pode reduzir a probabilidade de falhas (GUZZON, 2009). Segundo Fogliatto e Ribeiro (2009), para calcular a confiabilidade usa-se o conceito binário de probabilidade: um equipamento opera ou não. A confiabilidade de um equipamento em dado instante é representada por uma probabilidade e por isso está compreendida entre 0 e 1. Grosh (1989) observou que, para a determinação da confiabilidade por técnicas quantitativas, devem ser observadas as incertezas dos parâmetros que as descrevem, dada a natureza estocástica das variáveis. Salgado (2008) aponta a importância da quantidade e qualidade dos dados para a utilização de técnicas probabilísticas.

Em síntese, confiabilidade é a probabilidade de um sistema desempenhar sua função, isento de falhas, por um determinado período de tempo e sob condições 
especificadas (NBR 5462,1994). Falha é o estado de inoperância de um sistema ou subsistema que deixa de executar a função para a qual foi especificado (RAUSAND e HOYLAND, 2004).

Outra função de interesse é a manutenibilidade. Manutenibilidade é a probabilidade de um componente ser restaurado a uma dada condição, em um dado período de tempo, se a manutenção for feita por profissionais, procedimentos e recursos prescritos (NBR ISO 14224, 2011, p.182). Blanchard et al (1995) definem manutenibilidade como uma característica de projeto e de instalação expressa como a probabilidade que, dado que uma falha ocorreu, será reparada em até um dado intervalo de tempo. Tal como a confiabilidade, a manutenibilidade é probabilística. Ambas se valem de modelos conhecidos para ajuste de dados de campo.

Os modelos mais utilizados para descrever funções de confiabilidade são as distribuições de probabilidade exponencial, Weibull, gamma, lognormal e normal. A variável a ser ajustada é o tempo até a falha de equipamentos (FOGLIATTO e RIBEIRO, 2009). Três funções são importantes: a função densidade de probabilidade de falha $f(t)$, a função confiabilidade $R(t)$, e a função de risco $h(t)$ (IRESON et al., 1996), Sellitto (2005) aponta o MTTF (tempo médio até a falha), obtenível das funções, como grandeza capaz de sintetizar estudos de confiabilidade.

A distribuição exponencial descreve o tempo até a falha de sistemas sem memória, ou seja, nos quais o passar do tempo não altera a probabilidade de falha. A distribuição gamma descreve o tempo até a falha de sistemas que operam com componentes em paralelo para a mesma função. A distribuição de Weibull descreve o tempo até a falha de sistemas que operam em série. A distribuição lognormal descreve o tempo até a falha para sistemas cuja falha se origina da multiplicação do efeito de infinitos fatores. Por fim, a distribuição normal descreve o tempo até a falha para sistemas cuja falha se origina da soma do efeito de infinitos fatores (DODSON e NOLAN, 2002; HAHN e SHAPIRO, 1967).

$\mathrm{Na}$ manutenção, um modelo especialmente importante é o de Weibull. O modelo Weibull consegue lidar com amostras de pequeno tamanho e variados comportamentos da taxa de falha, crescente, decrescente ou constante, segundo o valor do parâmetro de forma $\square$. Na função de risco $h(t)$, se $\square<1, h(t)$ é decrescente; se $\square=1, h(t)$ é constante; e se $\square>1, h(t)$ é crescente. A análise de Weibull pode identificar se a falha é um evento prematuro, casual ou ocasionada por desgaste, segundo o formato da função risco $h(t)$. Função risco $h(t)$ decrescente indica falhas 
prematuras; $h(t)$ constante indica falhas casuais ou aleatórias; e $h(t)$ decrescente indica falhas por desgaste. Segundo, para que se tenha uma análise precisa 0 histórico dos dados de intervenções de manutenção deve ter boa acuracidade.

Há casos particulares notáveis da distribuição de Weibull. Se $\square=1$, Weibull recai na exponencial; se $\square=2$, Weibull recai na distribuição de Rayleigh; se $\square=2,5$, Weibull tem comportamento semelhante à lognormal; se $\square=3,2$, Weibull tem comportamento semelhante à normal (LEWIS, 1996; KAPUR e LAMBERSON, 1977). A distribuição exponencial é um caso particular da distribuição de Weibull com parâmetro de forma

A análise pela taxa de falha $h(t)$ se vale da chamada curva da banheira, que representa as três fases de vida do equipamento. Cada fase está associada a um tipo de comportamento da $h(t)$, segundo o fator de forma da distribuição de Weibull associada (LAFRAIA, 2001).

Sellitto (2005) indica uma estratégia de manutenção para cada fase. A primeira fase é a da mortalidade infantil. Nesta fase ocorrem falhas prematuras, tais como erros de fabricação, instalação ou uso de materiais inadequados. A melhor estratégia de manutenção é a corretiva. A segunda fase é a da maturidade, na qual o equipamento apresenta taxa constante de falhas causadas por eventos casuais ou aleatórios. As causas podem ser erro humano, fator de segurança insuficiente ou erros de operação. Para esta fase, vale a estratégia de manutenção preditiva e a gestão de boas práticas de manutenção, como ocorre em programas baseados na TPM. A terceira e última fase é a de mortalidade senil. Nesta fase, aumenta a taxa de falhas devido ao envelhecimento, degradação ou fim da vida de projeto. A estratégia ideal é a manutenção preventiva ou reforma.

$\mathrm{Na}$ Figura 1, visualizam-se na curva da banheira as fases de mortalidade infantil, maturidade e mortalidade senil com os seus respectivos fatores de forma 
Figura 1: Curva da banheira (SELLITTO, 2005)

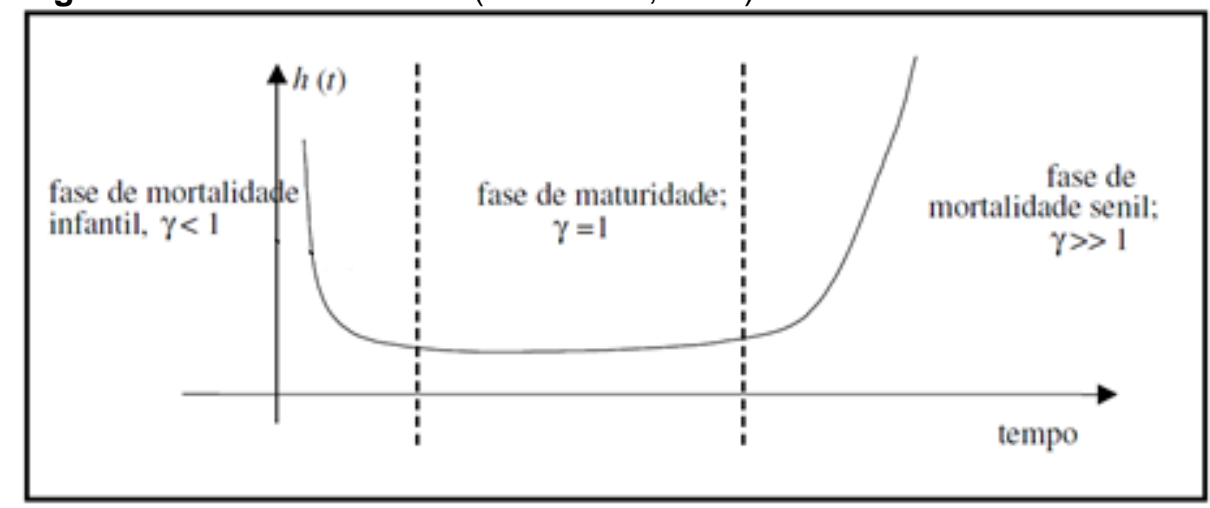

O modelo de confiabilidade baseado na distribuição de Weibull é dado pelas equações de (1) a (4) (FOGLIATTO e RIBEIRO, 2009).

$$
\begin{gathered}
f(t)=\frac{\gamma}{\theta}\left(\frac{t-t_{0}}{\theta}\right)^{\gamma-1} e\left[-\left(\frac{t-t_{0}}{\theta}\right)^{\gamma}\right] 0 \leq t \leq \infty \\
h(t)=\frac{\gamma}{\theta}\left(\frac{t-t_{0}}{\theta}\right)^{\gamma-1}(2) \\
R(t)=e^{-\left(\frac{t-t_{0}}{\theta}\right)^{\gamma}}(3) \\
M T B F=t_{0}+\theta^{1 / \gamma} \Gamma\left(1+\frac{1}{\gamma}\right)
\end{gathered}
$$

Em que:

$t_{0}=$ tempo isento de falha;

$\gamma=$ parâmetro de forma;

$\theta$ = parâmetro de escala; $\mathrm{e}$

$t=$ tempo até a falha.

As distribuições normal e lognormal são úteis para a análise de mantenabilidade. A normal se ajusta melhor a casos em que o reparo é composto por atividades em série, tal como em desmontagem e remontagem de máquinas. A 
lognormal se ajusta melhor a atividades cognitivas, tal como em reparos que exijam pesquisa de defeito (MENGUE e SELLITTO, 2013). A lei de Weber-Fetcher sobre atividades psicofísicas pode ser usada para reforçar esta evidência.

Por fim, a disponibilidade de um equipamento ou sistema é calculada pela equação (5) (RAUSAND e HOYLAND, 2004).

$$
A v(t)=\frac{M T B F}{M T B F+M T T R}
$$

\section{Em que:}

$M T B F$ = tempo médio entre falhas; e

$M T T R=$ tempo médio até o reparo.

A disponibilidade $A v(t)$ informa sobre a probabilidade de que um dado equipamento esteja disponível para operação, dado que foi requisitado. Sua gestão envolve tanto o aumento do MTBF como a redução do MTTR.

Leão e Santos (2009) sugerem que o aumento da disponibilidade do equipamento ocorra por redução do tempo de manutenção utilizando conceitos semelhantes à Troca Rápida de Ferramenta (TRF) do Sistema Toyota de Produção para a troca de partes frágeis. Para Santos (2006), uma maneira de aumentar a disponibilidade de equipamentos é aplicar um programa de desenvolvimento de fornecedores que confira qualidade assegurada às peças sobressalentes e mais robustez ao projeto de máquinas. Para isso, é necessário estabelecer requisitos relacionados à mantenabilidade nos projetos e confiabilidade nos produtos entregues por fornecedores, sejam peças, ou máquinas.

\section{A PESQUISA}

O objetivo deste artigo é propor uma estratégia de manutenção e um conjunto de melhorias para aumento da disponibilidade em um posto de compressão de gases residuais do processo de destilação do petróleo, composto por dois compressores alternativos $\mathrm{A}$ e $\mathrm{B}$ em uma refinaria da indústria petrolífera. $\mathrm{O}$ método de pesquisa foi a modelagem quantitativa. Na modelagem quantitativa, uma situação de interesse é representada por meio de um modelo matemático, no qual variáveis 
numéricas se relacionam por equações, proporcionando o tratamento da situação de uma forma sistemática. Em suma, na modelagem quantitativa são necessárias variáveis e equações, formando um modelo descrito em linguagem matemática, que pode usar técnicas analíticas para calcular propriedades atuais e estimar respostas a estímulos, desde que estes possam ser expressos por variáveis numéricas (MORABITO e PUREZA, 2010). Neste artigo, a resposta à questão de pesquisa é obtida pela análise do modelo probabilístico que se construiu para a variável tempo até a falha, tanto dos equipamentos individuais quanto do posto de compressores.

O método de trabalho foi: delimitação do sistema estudado (posto de compressão de gases residuais); levantamento histórico de intervalos entre falhas e de tempos para reparo do posto de compressão; modelagem, pela distribuição de Weibull, dos intervalos entre falhas e, identificação do ponto no ciclo de vida em que o equipamento se encontra (mortalidade infantil, maturidade, ou mortalidade senil); modelagem, pela distribuição lognormal, dos tempos até o reparo; com os valores médios das duas distribuições (MTBF e MTTR), cálculo da disponibilidade das máquinas e do posto de compressão; escolha da estratégia de manutenção para o posto de compressão (corretiva, preditiva, ou preventiva, segundo a fase no ciclo de vida) e análise por estratificação de falhas da atual estratégia de manutenção para este posto de trabalho; e, com base na análise, propor uma política de manutenção e melhorias de instrumentação das máquinas que compoe o posto de compressão.

Para as modelagens, foi usado o software modelador ProConf 2000. O Proconf 2000 testa ajustes de dados de amostras de tempos de falha e de reparo às distribuições exponencial, Weibull, gamma, lognormal e normal. O ajuste passa pelos testes do qui-quadrado e de Kolmogorov-Smirnov, fornecendo gráficos e análises matemáticas dos dados de falha (FRITSCH e RIBEIRO, 1998). Os dados de falha e de reparo foram obtidos do sistema de informação da empresa. Aplicações similares na mesma indústria, a petrolífera, foram feitas em Wüttke e Sellitto (2008) e Mengue e Sellitto (2012).

Um compressor alternativo é uma máquina composta por subsistemas, cujos modos de falha levam à falha geral ou à perda da função: basta um subsistema falhar que o equipamento falha, o que remete à distribuição de Weibull. No entanto, a parada de um compressor não indisponibiliza o posto de compressão, formado por mais um compressor idêntico, caracterizando um sistema em redundância. Os principais subsistemas que compõem este compressor são as válvulas de sucção e 
descarga, os cilindros de compressão (haste, aneis de guia e desgaste, camisas e embolos), as cruzetas, os guias das cruzetas, o sistema de lubrificação, o acionador, a alimentação elétrica e a instrumentação de controle. Sua função é comprimir vapores e gases residuais da torre de destilação de petróleo, levando-os à pressão adequada para aproveitamento como combustível em um turbogerador de energia elétrica. A perda da função compressão do posto implica redução de carga de processamento da unidade, alívio dos gases residuais para queima na tocha e consequente ataque ambiental severo.

\subsection{Modelagens}

A partir do sistema de informação da empresa, foram identificados e levantados dados de intervenções de manutenção de emergência entre 2005 e 2013. Foram consideradas apenas paradas de emergência. Para cada intervenção de manutenção, existe um registro feito pela Engenharia de Manutenção da empresa, de onde foram coletados os dados, em dias, das Tabelas 1 e 2.

Tabela 1 - Compressor A: Tempo até o reparo e tempo entre falhas.

\begin{tabular}{cccccc}
\hline \multicolumn{2}{c}{ Tempo até o reparo (TTR, dias) } & \multicolumn{3}{c}{ Tempo entre falhas (TBF, dias) } \\
\hline 120 & 219 & 1 & 415 & 27 & 201 \\
66 & 8 & 2 & 21 & 201 & 14 \\
8 & 938 & & 84 & 91 & 19 \\
1 & 10 & 188 & 75 & 385 \\
4 & 553 & 435 & 36 & \\
\hline
\end{tabular}

Fonte: Sistema de informação da empresa

Tabela 2 - Compressor B: Tempo até o reparo e tempo entre falhas.

\begin{tabular}{cccccc}
\hline \multicolumn{2}{c}{ Tempo até o reparo (TTR, dias) } & \multicolumn{3}{c}{ Tempo entre falhas (TBF, dias) } \\
\hline 3 & 162 & 41 & 495 & 225 & 304 \\
91 & 3 & 208 & 42 & 4 & 207 \\
49 & 52 & 7 & 129 & 4 & 114 \\
5 & 3 & 5 & 94 & 6 & 1551 \\
35 & 4 & & 595 & 93 & \\
\hline
\end{tabular}

Fonte: Sistema de informação da empresa 
Segue a modelagem do tempo até o reparo (TTR) para os dois compressores. A hipótese de que os dados individuais se ajustem à lognormal não foi rejeitada. Testes de aderência são apresentados nas Figuras 2 e 3.

Figura 2 - Teste de aderência lognormal para o tempo até o reparo do compressor A

Teste do Qui-Quadrado: $\square 2=2,58$ com 1 grau de liberdade Nível de Significância $=0,1083$

Teste de Kolmogorov-Smirnov: DN = 0,2027 Nível de Significância = 0,1967

A hipótese de que a população segue o modelo Lognormal não pode ser rejeitada.

Fonte: ProConf (2000)

Figura 3 - Teste de aderência lognormal para o tempo até o reparo do compressor B Teste do Qui-Quadrado: $\square 2=0,46$ com 1 grau de liberdade Nível de Significância =0,496 Teste de Kolmogorov-Smirnov: DN = 0,2227 Nível de Significância = 0,0581

A hipótese de que a população segue o modelo Lognormal não pode ser rejeitada.

Fonte: ProConf (2000)

Uma análise adicional é o papel de probabilidade lognormal para os TTR dos compressores A e B, apresentados nas Figuras 4 e 5 respectivamente.

Figura 4 - Papel de probabilidade lognormal para TTR do compressor A

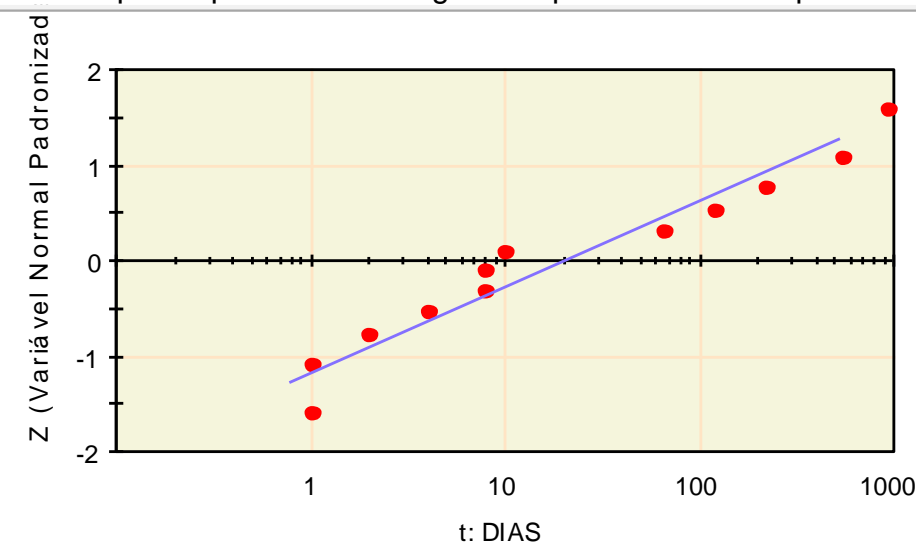

Fonte: ProConf (2000)

Figura 5 - Papel de probabilidade lognormal para TTR do compressor B

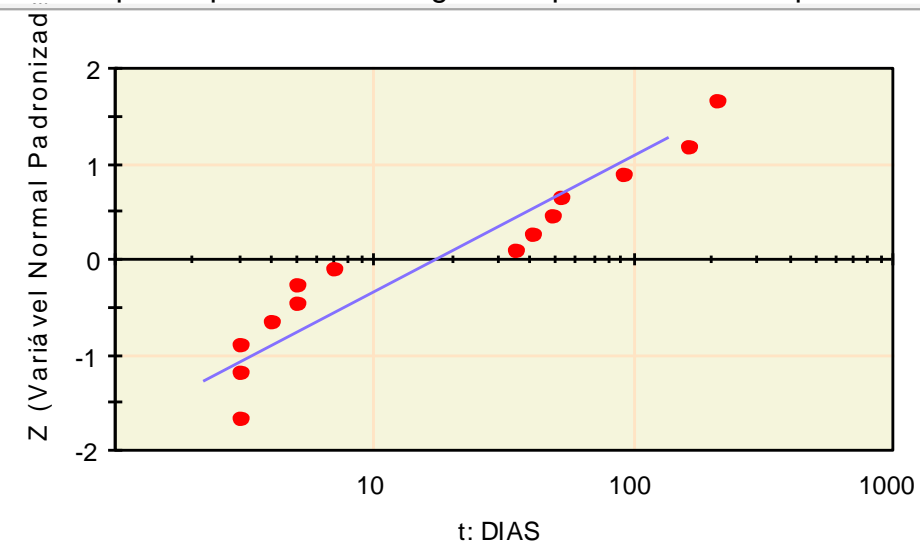

Fonte: ProConf (2000)

Revista Produção Online, Florianópolis, SC, v.16, n. 1, p. 77-103, jan./mar. 2016. 
O tempo médio para o reparo MTTR para o Compressor A é de 292 dias. O ajuste é apresentado na Figura 6. A função mantenabilidade é representada pela Figura 7.

Figura 6 - Modelo lognormal para TTR do compresor A

Média do logarítmo dos dados $=3,0055$
$95 \%$ do Intervalo de Confiança para a média do logarítmo dos dados: 1,5425 até 4,$4685 ;$
Variância do logaritmo dos dados $=5,3492$
$95 \%$ do Intervalo de Confiança para a variância do logaritmo dos dados: 2,928 até 16,8283
MTTR $=292,9866$
$95 \%$ do Intervalo de Confiança para o tempo médio até a falha: 31,9264 até 4372,594
Var. do tempo médio até a falha $=1,7979 \mathrm{E}+07$
$t_{10}=1,0419$
$t_{50}=20,1967$

Fonte: ProConf (2000)

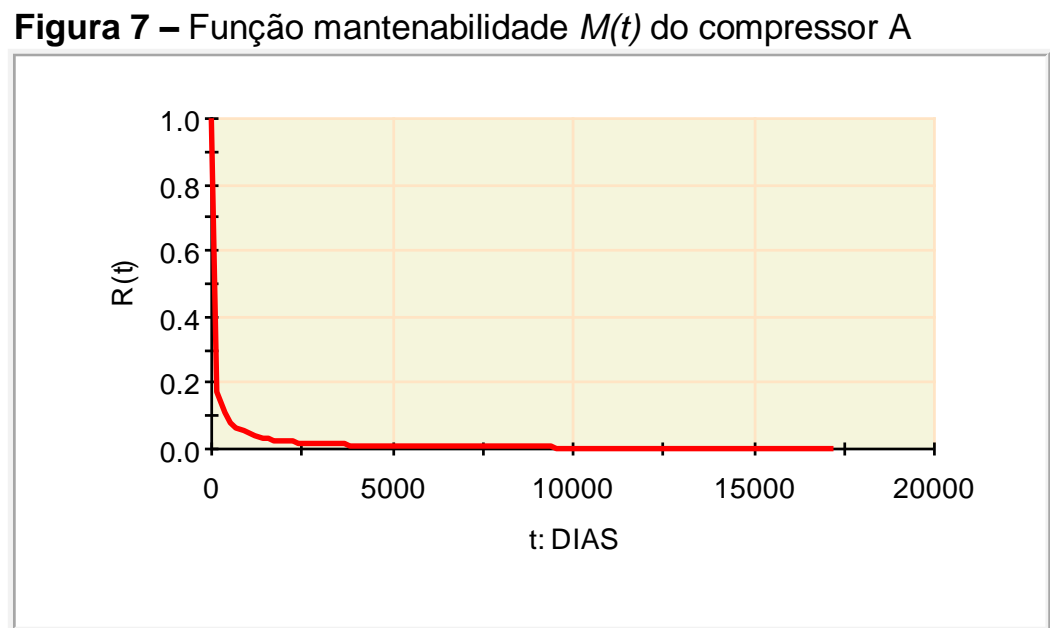

Fonte: ProConf (2000)

O tempo médio para reparo MTTR para o Compressor B é de 55 dias. O ajuste oferecido pelo ProConf 2000 é apresentado na Figura 8. A função mantenabilidade é representada pela Figura 9. 
Figura 8 - Modelo lognormal para o tempo até o reparo compress. B

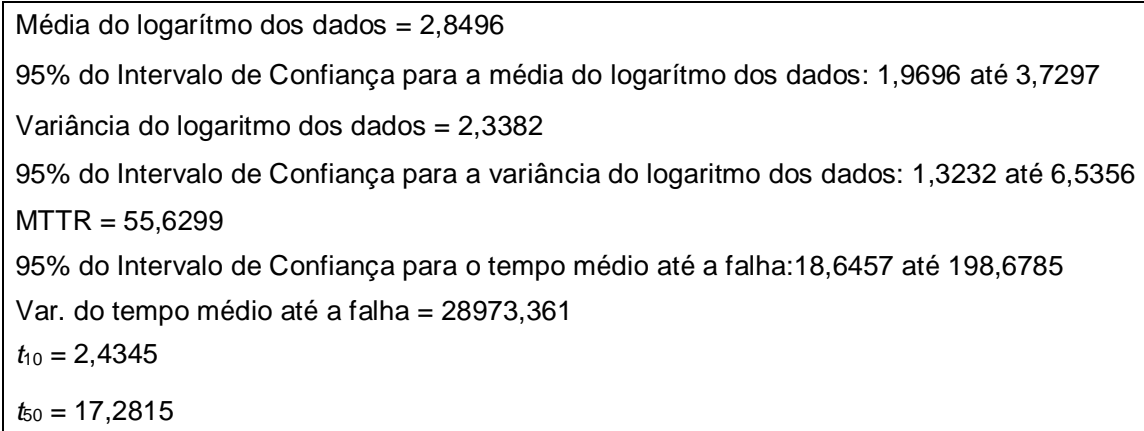

Fonte: ProConf (2000)

Figura 9 - Função mantenabilidade $M(t)$ do compressor B

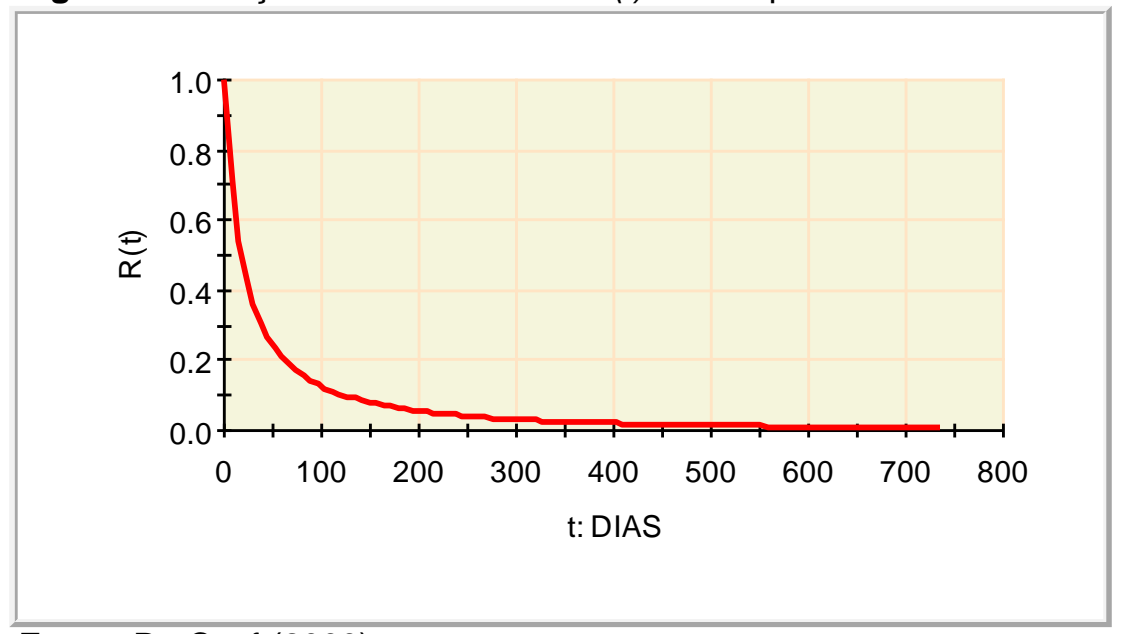

Fonte: ProConf (2000)

Para o tempo entre falhas (TBF), o ProConf 2000 não rejeitou a hipótese de que os dados se ajustem ao modelo Weibull. Testes de aderência são apresentados nas Figuras 10 e 11.

Figura 10 - Teste de aderência Weibull para TBF do compressor A

Teste do Qui-Quadrado: $\square 2=1,63$ com 1 grau de liberdade Nível de Significância = 0,2026

Teste de Kolmogorov-Smirnov: $\mathrm{DN}=0,1368$ Nível de Significância = 0,2961

A hipótese de que a população segue o modelo Weibull não pode ser rejeitada.

Fonte: ProConf (2000)

Figura 11 - Teste de aderência Weibull para TBF do compressor B

Teste do Qui-Quadrado: $\square 2=0,87$ com 1 grau de liberdade Nível de Significância = 0,3502

Teste de Kolmogorov-Smirnov: DN = 0,1771 Nível de Significância $=0,1852$

A hipótese de que a população segue o modelo Weibull não pode ser rejeitada.

Fonte: ProConf (2000)

O papel de probabilidade dos TBF dos compressores A e B para o modelo Weibull são apresentados nas Figuras 12 e 13. As respectivas funções confiabilidade são apresentadas nas Figuras 14 e 15.

Revista Produção Online, Florianópolis, SC, v.16, n. 1, p. 77-103, jan./mar. 2016. 
Figura 12 - Papel de probababilidade Weibull para TBF do compressor A

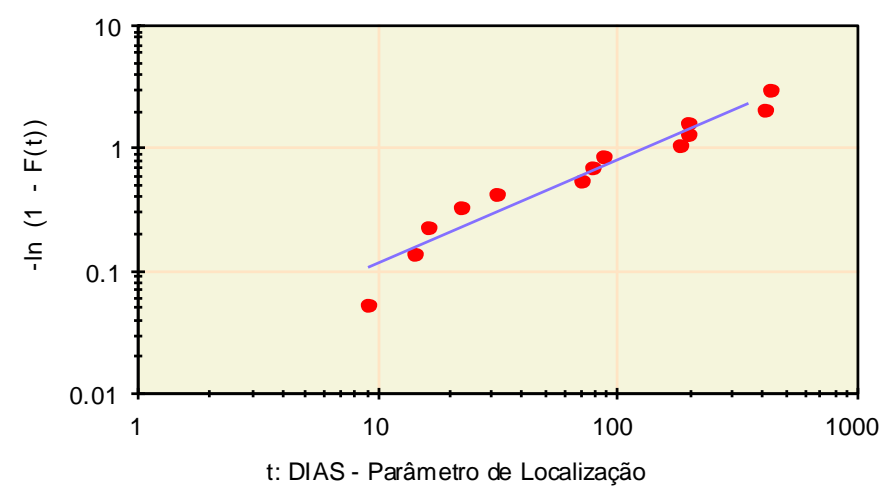

Fonte: ProConf (2000)

Figura 13 - Papel de probababilidade Weibull para TBF do compressor B

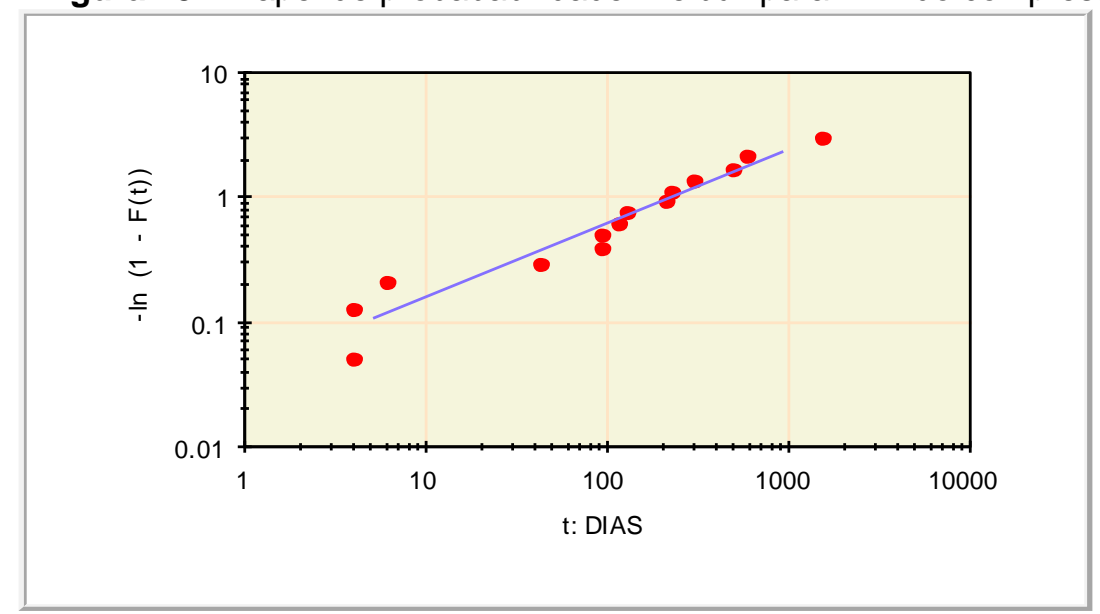

Fonte: ProConf (2000)

Figura 14 - Função confiabilidade $R(t)$ para o compressor $\mathrm{A}$

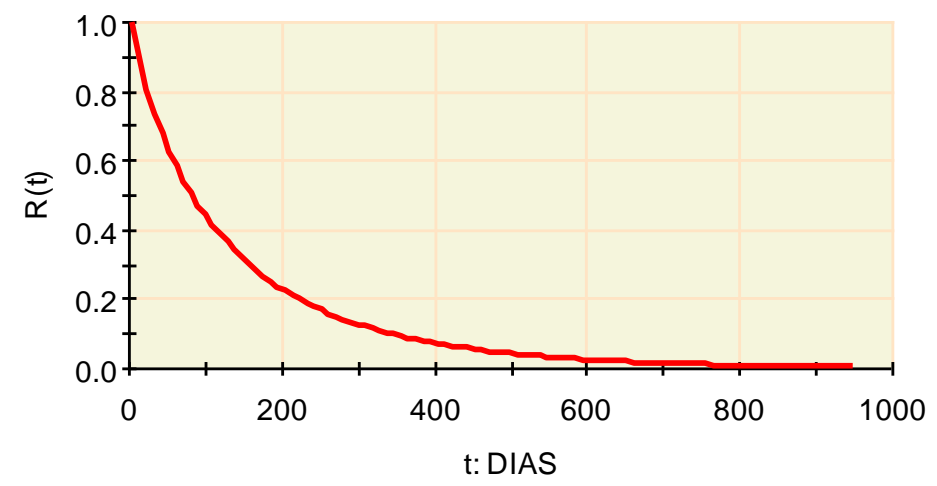

Fonte: ProConf (2000) 
Figura 15 - Função confiabilidade $R(t)$ para o compressor B

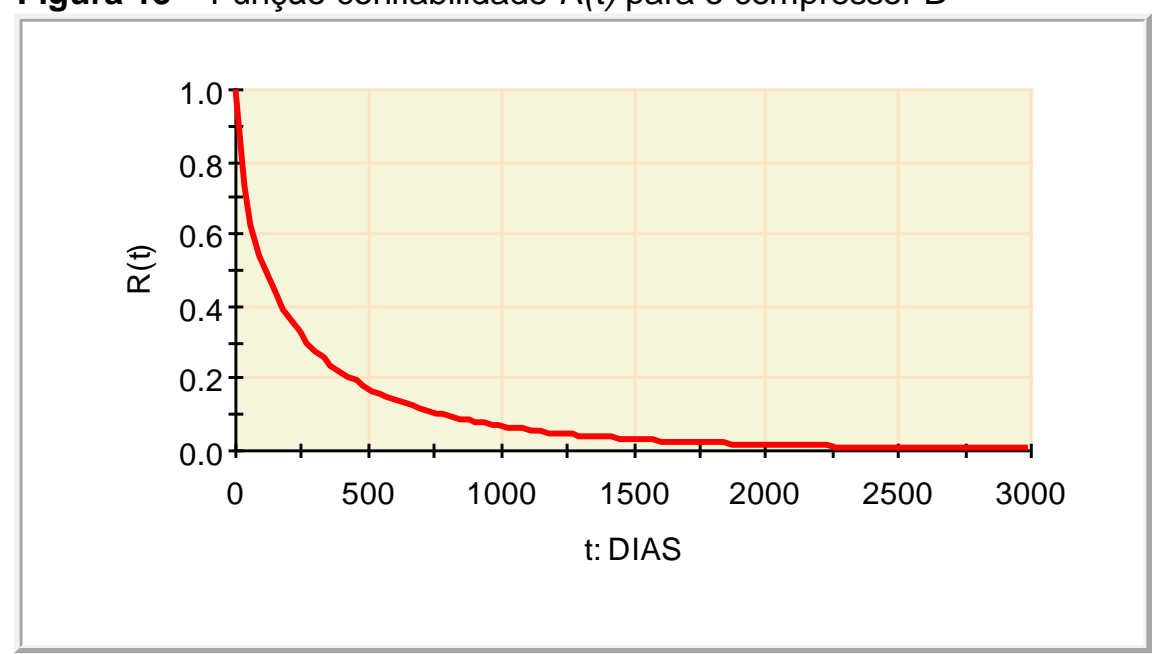

Fonte: ProConf (2000)

A modelagem para os TBF pelo modelo Weibull é apresentada nas Figuras 16 e 17. Além da estimativa por máxima verossimilhança, o ProConf 2000 oferece uma estimativa não tendenciosa, corrigida por algoritmo específico (SELLITTO et al., 2002). Para este artigo, vale a estimativa não tendenciosa. O fator de forma da distribuição assumida para explicar os TBF dos compressores indica sua posição mais provável na curva da banheira e sugere a estratégia de manutenção com mais probabilidade de sucesso.

Figura 16 - Modelo Weibull para BF para o compress. A

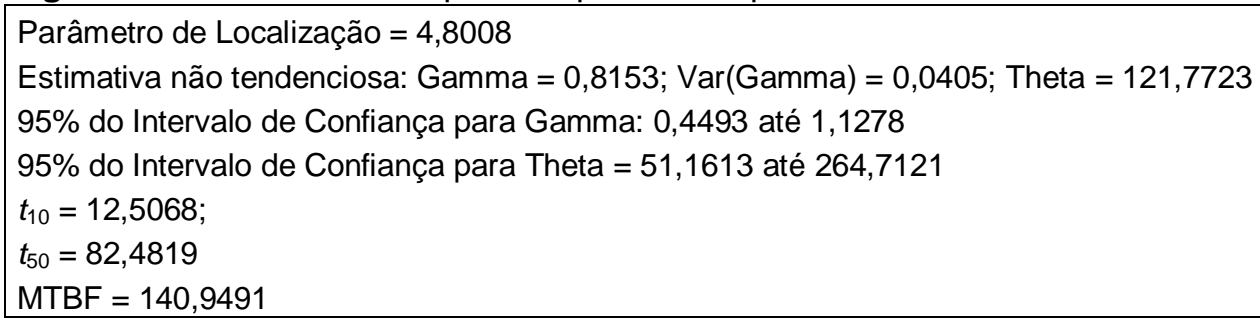

Fonte: ProConf (2000)

Figura 17 - Modelo Weibull para TBF para o compressor B

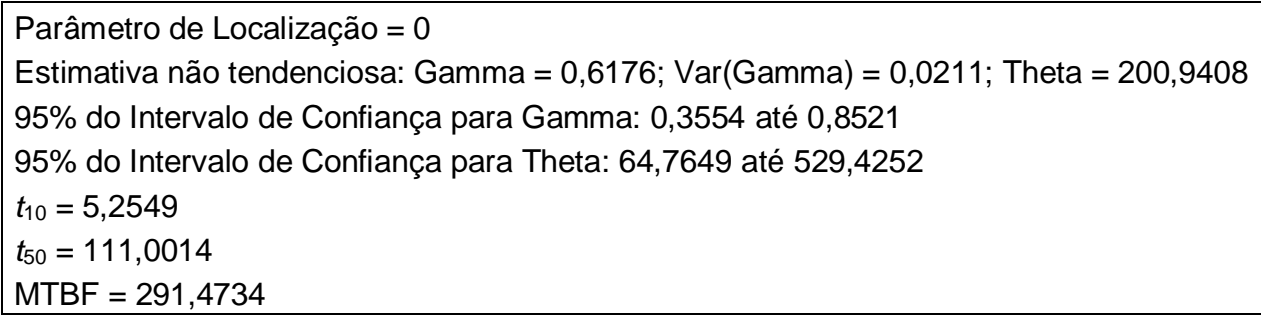

Fonte: ProConf (2000) 
Os MTBF e MTTR do compressor A são 140,9 e 292,9 dias, respectivamente. Pala equação (6), a disponibilidade de A é de cerca de $32,5 \%$.

$$
A v(t)=\frac{140,9}{140,9+292,9}=32,5 \%
$$

Os MTBF e MTTR do compressor B são 291,4 e 55,6 dias, respectivamente. Pela equação (7), a disponibilidade de A é de cerca de $84 \%$.

$$
A v(t)=\frac{291,4}{291,4+55,6}=83,9 \%
$$

A baixa disponibilidade encontrada nas máquinas individuais pode ser explicada pela redundância. Consultando a literatura sobre compressores em redundância observa-se em Liang et al. (2012) que deficiências de manutenibilidade e confiabilidade em máquinas individuais podem ser escondidas por sistemas redundantes. Para verificar esta hipótese, foi calculada a disponibilidade do posto de compressão, considerando a operação conjunta dos dois compressores. Os dados conjuntos, os testes de hipóteses para TTR, o modelo lognormal para TTR, os testes de hipóteses para TBF, o modelo gamma (adequado para paralelismos e redundâncias) para TBF são apresentados respectivamente na Tabela 3 e Figuras de 18 a 21.

Tabela 3 - TTR e TBF para o posto de compressores.

\begin{tabular}{cccc}
\hline \multicolumn{2}{c}{ Tempo até o reparo (TTR, dias) } & \multicolumn{2}{c}{ Tempo entre falhas (TBF, dias) } \\
\hline 3 & 4 & 498 & 93 \\
93 & 41 & 1334 & 304 \\
3 & 7 & 4 & 207 \\
52 & 5 & 4 & 1665 \\
3 & & 6 & 6 \\
\hline
\end{tabular}

Fonte: Sistema de informação da empresa

Figura 18 - Teste de aderência lognormal para TTR do posto

Teste do Qui-Quadrado: $\square 2=1,27$ com 1 grau de liberdade Nível de Significância $=0,2606$

Teste de Kolmogorov-Smirnov: DN = 0,2645 Nível de Significância $=0,0693$

A hipótese de que a população segue o modelo Lognormal não pode ser rejeitada.

Fonte: ProConf (2000) 
Figura 19 - Modelo lognormal para TTR do posto de compressores

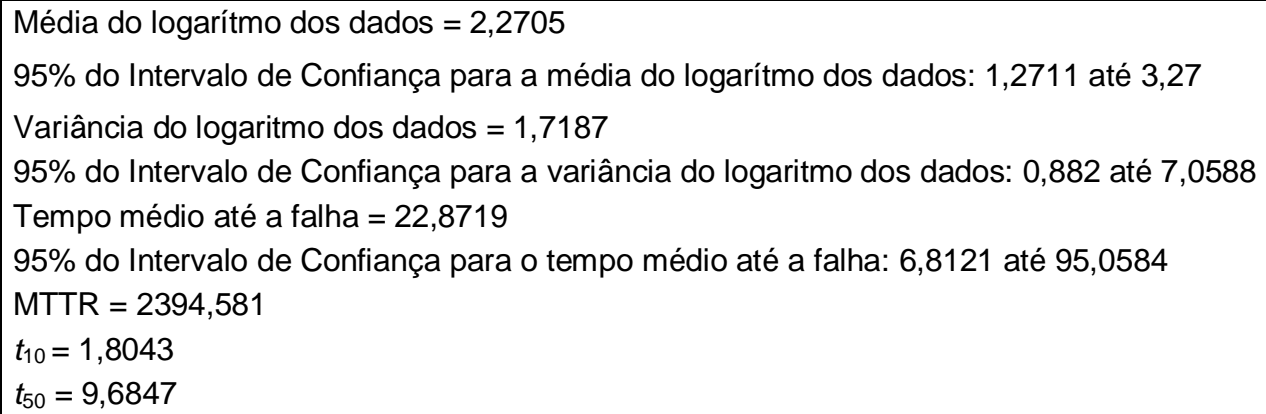

Fonte: ProConf (2000)

Figura 20 - Teste de aderência gamma para TBF do posto de compressores Teste do Qui-Quadrado: $\square 2=0,74$ com 1 graus de liberdade Nível de Significância = 0,3909 Teste de Kolmogorov-Smirnov: DN = 0,2195 Nível de Significância = 0,1813 A hipótese de que a população segue o modelo Gamma não pode ser rejeitada.

Fonte: ProConf (2000)

Figura 21 - Modelo Gamma para TBF do posto de compressores

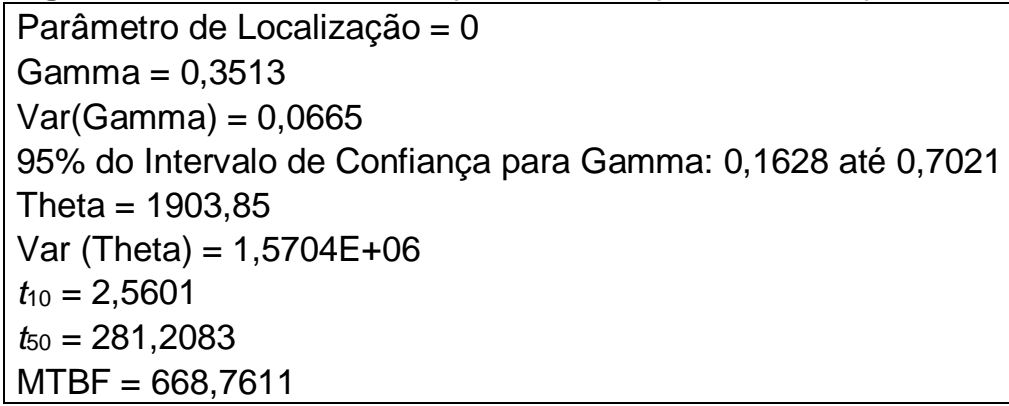

Os MTBF e MTTR do posto de compressão são respectivamente 668,8 e 22,8 dias. Pela equação (8), a disponibilidade é de cerca de 96,7\%, elevada e satisfatória, apesar das baixas disponibilidades individuais.

$$
A v(t)=\frac{668,8}{668,8+22,8}=96,7 \%
$$

\section{ESTRATÉGIA DE MANUTENÇÃO DOS EQUIPAMENTOS}

Pela análise de Weibull, obteve-se um fator de forma para os compressores A e $B$ de 0,81 e 0,61, respectivamente. Nas Figuras 22 e 23, apresenta-se a posição 
mais provável que os equipamentos ocupam na curva da banheira. Para ambos, a estratégia indicada é a manutenção corretiva.

Figura 22 - Posição do compressor A na curva da banheira

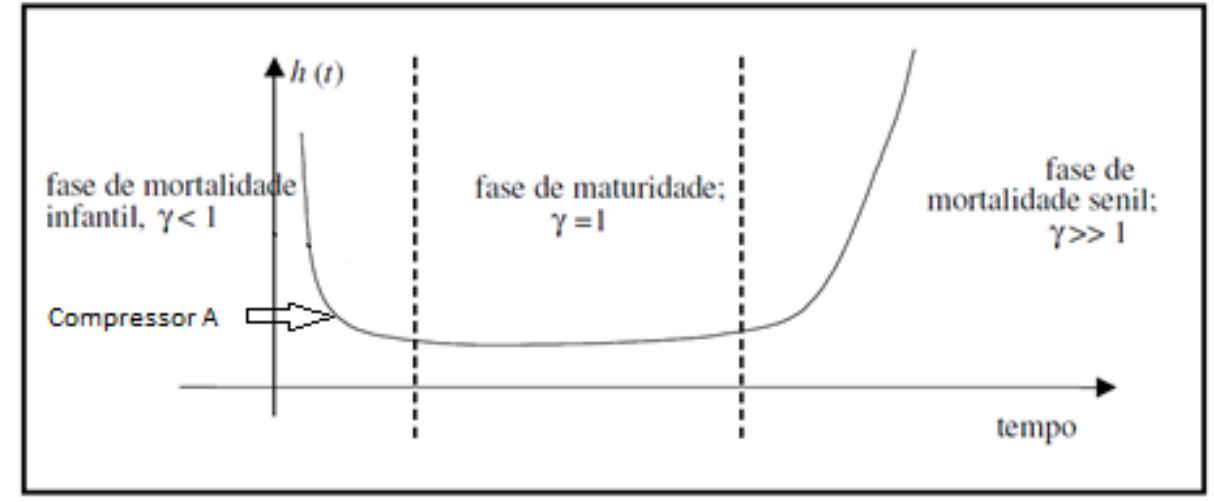

Figura 23 - Posição do compressor B na curva da banheira

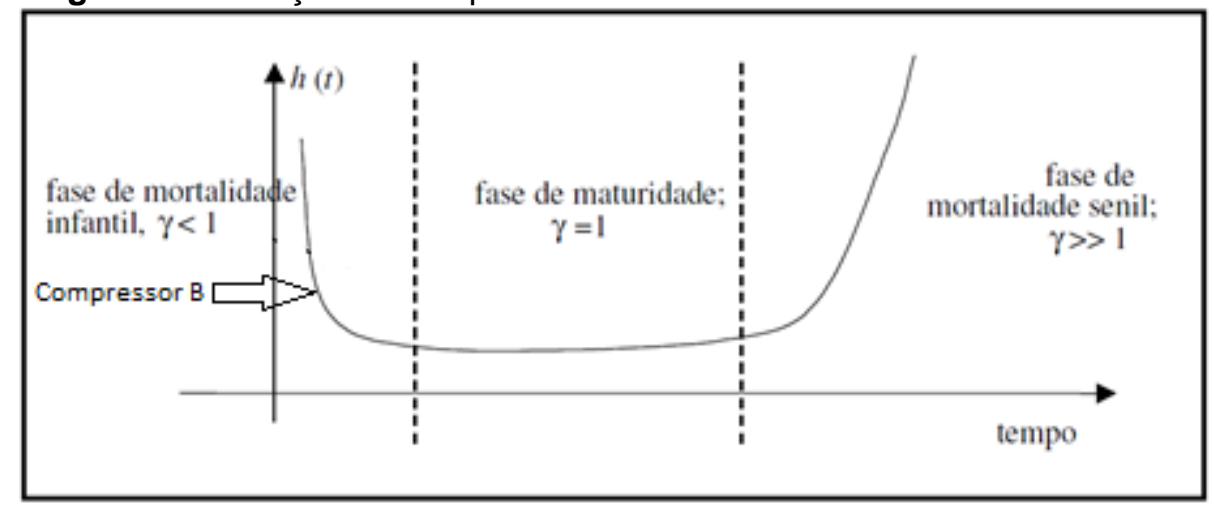

Comparando com dois estudos similares, ambos na indústria petrolífera, em Wuttke e Sellitto (2008) a estratégia definida foi a manutenção preditiva (disponibilidade = 99,35\%); em Mengue e Sellitto (2012), a estratégia de manutenção apontada foi a manutenção corretiva (disponibilidade = 96,73\%).

A estratégia de manutenção atualmente adotada é a preventiva, combinada com algumas atividades preditivas. Existe uma programação de intervenções preventivas a cada 4.000 horas, 8.000 horas, e 16.000 horas, com escopos diferentes de intervenções. Consultando a literatura, observa-se que, segundo Moubray (1996), se um determinado equipamento não possui um modo predominante e característico de falha, revisões programadas podem contribuir pouco para aumentar a confiabilidade. Neste caso a prática de manutenção preventiva é pouco eficaz. Entretanto os compressores, objeto deste estudo, tem 
modos de falha bem definidos, o que tem até agora justificado a estratégia de manutenção preventiva.

As principais falhas que têm sido observadas são apresentadas na Tabela 4.

Tabela 4 - Diagnóstico das falhas ao longo do tempo

\begin{tabular}{lc}
\hline \multicolumn{1}{c}{ Tipo de falhas } & Incidência das falhas \\
\hline Recirculação nas válvulas causada por sujeira no processo & $55 \%$ \\
Desgaste dos aneis de segmento limitando a capacidade de compressão & $20 \%$ \\
Desgaste dos aneis guia causando roçamento dos cilindros na camisa & $15 \%$ \\
Vazamento de óleo e gás causados por desgaste na selagem & $5 \%$ \\
\hline
\end{tabular}

Fonte: Sistema de informação da empresa

Observa-se que a principal falha é a recirculação nas válvulas causada por sujeira no processo. Esta é uma falha inerente do processo e caracterizada pela impossibilidade de acompanhamento preditivo. Seguem os desgastes dos aneis de compressão e dos aneis de guia dos cilindros, também diretamente ligados às impurezas dos gases comprimidos, pois as falhas acontecem em virtude de deficiências estruturais do projeto das máquinas ou do processo produtivo do refino.

Os gases residuais do processo de destilação contem na sua composição o $\mathrm{H}_{2} \mathrm{~S}$ (sulfeto de Hidrogênio). O sulfeto de hidrogênio é um gás incolor, de cheiro desagradável característico, extremamente tóxico e mais denso que o ar. (MAINER, 2005). Esse gás quando dissolvido em meio aquoso promove a redução do ph favorecendo o processo corrosivo do aço carbono formando o FeS (sulfeto de ferro). (LIMA, 2011). As tubulações que trazem os gases residuais até a sucção dos compressores são de aço carbono. O filme de FeS se forma nas paredes e com o fluxo e as vibrações produzidas pelo fluido se desprendem e adentram a máquina.

A carcaça dos compressores também sofre a ação da formação de FeS (sulfeto de ferro) ocasionada pelo $\mathrm{H}_{2} \mathrm{~S}$, uma vez que é fabricada de aço fundido. As válvulas, apontadas neste estudo como o principal agente de falhas, são de material inoxidável e não reagem com $0 \mathrm{H}_{2} \mathrm{~S}$. É a sujeira das tubulações de sucção que causam aquecimento e a falha desses componentes.

Para as atividades preditivas, a equipe de manutenção utiliza-se de coletas e monitoração de dados, tais como: vibração, temperatura, e análise de contaminação do óleo lubrificante. Após iniciada a operação do equipamento, a monitoração ajuda a predizer o momento em que aumenta a chance de falha. $O$ objetivo do monitoramento é acompanhar falhas em progresso para evitar quebras. 
A estratégia de operação adotada pela refinaria para esses compressores tem sido, por mais de vinte anos, trabalhar com uma só máquina até a quebra enquanto a máquina reserva fica desmontada e as válvulas acondicionadas no almoxarifado, evitando o emperramento das válvulas e o acúmulo de FeS nos cilindros formados pela reação do $\mathrm{H}_{2} \mathrm{~S}$ com o aço, que também ocasionam desgaste prematuro dos aneis de compressão e de guia dos cilindros. Esta é a razão da baixa disponibilidade individual dos compressores.

Os resultados de pesquisa apontam que ambos os equipamentos se encontram na fase de mortalidade infantil. Nesse caso, conforme explica Sellitto (2005), a Engenharia de Manutenção pode optar pela manutenção corretiva, cujo objetivo é reduzir ou até eliminar as falhas prematuras, originadas principalmente de problemas de projeto ou de instalação. Esta estratégia implica largos investimentos em melhorias no equipamento e longos tempos de indisponibilidade para reformas e melhorias que eliminem as falhas estruturais detectadas.

A estratégia de manutenção corretiva não é desconhecida da empresa, pois foi usada no posto de compressores até o ano de 2011. Neste ano, iniciou o processamento do petróleo do pré-sal, havendo necessidade de aumento da produtividade e redução dos custos do refino para cobrir os investimentos feitos na extração. Com isto, não foi mais possível manter as melhorias e principalmente, com a nova matéria-prima, inadequações de projeto apareceram, o que caracteriza a mortalidade infantil. Adicionalmente, a disponibilidade do posto de compressão, $96,7 \%$, não atende mais às novas demandas de produtividade da planta.

\section{SUGESTÕES PARA AUMENTAR A DISPONIBILIDADE}

Com a demanda crescente do mercado pelos derivados de petróleo e a capacidade restrita da refinaria, uma parada no posto de compressores implica diminuição da carga de processamento da unidade de destilação de $10.000 \mathrm{~m}^{3}$ para $7.000 \mathrm{~m}^{3}$, gerando prejuízos diários na ordem de \$21.000,00 (considerando que a perda mínima no faturamento é de $\$ 7,00$ por $\mathrm{m}^{3}$ não processado), consequente risco de desabastecimento do mercado forçando a empresa importar derivados para cumprir com os compromissos com seus clientes. O meio ambiente é afetado pelo descarte dos gases e a empresa fica sujeita a explicações aos órgãos ambientais e a possíveis medidas administrativas tomadas por estes. 
Compressores alternativos são equipamentos-chave no processo de produção da indústria do refino de petróleo. Em se tratando de compressores alternativos, os fabricantes afirmam que o melhor para máquinas com redundância é que, uma vez em funcionamento, seja mantida até sua fase senil. Portanto para o compressor parado é necessário que se tenha uma periodicidade para partida da máquina em vazio, ou seja, sem carga, apenas para lubrificar e manter condicionada a mecânica do equipamento.

Como em outros equipamentos na indústria do refino tais como bombas centrífugas, turbinas e outros compressores, o ideal para que se tenha mais confiabilidade nos sistemas com redundância é o regime de revesamento (reciprocating). Não é saudável que o equipamento fique parado por um longo período. O processo de revezamento consiste em implementar uma rotina de operação do equipamento determinando um intervalo em horas, e sistematimante efetuar a troca do equipamento em operação pelo que está parado.

No entanto, para compressores alternativos, as análises do comportamento dessas máquinas mostram que o ideal é que haja a partida e o compressor opere pelo maior tempo possível até apresentar sinais de desgaste e consequente falha. Os efeitos de uma parada e posterior partida são danosos e às vezes catastróficos devido ao desaquecimento dos componentes internos, o acumulo de vapores condensados nos cilindros, o pode gerar o chamado calço hidráulico, que leva à perda da máquina. Outro problema é a sujeira acumulada nas tubulações de sucção que são arrastadas para o interno das válvulas ocasionando aquecimento, recirculação e a falha desses componentes durante o processo de partida. Adicionalmente, são relevantes os aspectos de segurança pessoal, de instalações, e ambiental, dado que o risco é substancialmente maior durante o processo de partida, pois podem ocorrer vazamentos e contaminações por substâncias tóxicas, tais como o $\mathrm{H}_{2} \mathrm{~S}$.

Uma possível solução seria a substituição das tubulações de aço carbono por aço inox, estas não estariam sujeitas a reação $c 0 m \circ \mathrm{H}_{2} \mathrm{~S}$ e evitariam que o resíduo de sulfeto de ferro FeS ocasionasse a falha nas válvulas, porem implicaria numa intervenção muito expressiva com parada da unidade por muito tempo e sem grandes avanços em termos de confiabilidade para o posto e para a planta. Outra alternativa é a substituição dos compressores alternativos por compressores centrífugos, mais confiáveis e menos suscetíveis a falhas decorrentes de impurezas 
do processo, exigem investimento de aquisição de máquina e modificações de projeto. É uma alternativa viável que precisa ser vista de uma forma sistêmica, e pode ser objeto de um próximo estudo.

Seguem propostas de correção de problemas nas máquinas, quando cabível acompanhada de justificativa técnica.

\subsection{Condicionamento do compressor parado}

Gases oriundos de hidrocarbonetos são danosos aos componentes internos dos compressores (BLOCH e HOEFNER, 1996). O acúmulo de líquidos condensados em máquinas paradas provoca oxidação nas válvulas, cilindros e selagens das hastes dos cilindros (MAINIER e VIOLA, 2005). Para contornar esse problema, a manutenção retira as válvulas do compressor parado e as deixa acondicionadas para montagem quando houver a necessidade de entrar em operação. O tempo necessário para a montagem afeta a disponibilidade do posto, ja que as válvulas montadas não garantem o sucesso na partida. Devido os outros componentes estar expostos aos efeitos do $\mathrm{H}_{2} \mathrm{~S}$, o histórico de partidas mal sucedidas mostra o arraste de resíduos de FeS danificando as válvulas.

A proposta é que se mantenham as válvulas montadas e o compressor seja pressurizado com nitrogênio. $O$ gás Nitrogênio $\mathrm{N}_{2}$ é incolor, inodoro, não reativo, não poluente, e é considerado um gás inerte, pois não reage com o $\mathrm{H}_{2} \mathrm{~S}$ e tampouco com os componentes internos dos compressores.

\subsection{Monitoramento da vida útil das válvulas}

O que se vê na prática, e de acordo com Bloch e Hoefner (1996), o principal sintoma de que uma válvula está entrando em falha é o aumento da temperatura. $\mathrm{O}$ fenômeno da recirculação ocasionado pela sujeira do fluido produz temperaturas muito elevadas (acima de $100^{\circ} \mathrm{C}$ ), o monitoramento das temperaturas favorece o acompanhamento preditivo, permite impedir a quebra dos internos desses componentes e possibilita o planejamento de uma intervenção.

A instalação de um sensor termopar na tampa da válvula, cujo sinal em volt é interpretado por um monitor e na sequancia enviado na unidade ${ }^{\circ} \mathrm{C}$ para o SDCD 
(Sistema Digital de Controle Distribuído) onde é visualizado pelo operador ou pelo técnico de manutenção.

\subsection{Monitoramento do desgaste dos aneis de guia dos pistões e de compressão dos cilindros}

Para o monitoramento de desgaste dos aneis guia do pistão a solução proposta por Bloch e Hoefner (1996), é a instalação de um sensor de proximidade na carcaça da máquina, capaz de medir o deslocamento vertical da haste. Para medições de posição da haste, um sinal de cronometragem é usado para associar a posição do eixo de manivela com a posição da haste medida.

De posse das informações de queda da haste, é possível determinar o desgaste dos aneis de quia do pistão e fazer o acompanhamento preditivo desses componentes. A perda de compressão dos cilindros pode ser medida através de um sensor transdutor de pressão instalado na câmara de compressão. Com a informação da perda da função compressão pode-se avaliar o desgaste dos aneis de compressão.

\subsection{Válvula de dreno e filtro de sucção para partida segura}

Para impedir que os resíduos arrastados pelos gases penetrem nos compressores, um filtro deve ser instalado na tubulação de suç̧ão - esse componente deve informar as indicações de diferença de pressão entre montante e jusante $(\Delta P)$, a fim de permitir o operador saber quando o elemento filtrante estiver saturado e acionar a manutenção para a troca do elemento filtrante.

Se uma válvula de drenagem de condensados for colocada no ponto mais baixo da tubulação de sucção, será possível a retirada de líquidos condensados e resíduos que se acumulam a montante da válvula de sucção. Este modificação permitirá que a partida da máquina seja mais segura e sem riscos de saturação prematura do filtro. O objetivo aqui não é especificar tecnicamente os componentes e detalhes de projeto das melhorias na máquina, mas sim, a proposta da estratégia para a manutenção dos compressores e os meios para viabiliza-la. Neste caso o ponto ideal para a inserção do $\mathrm{N}_{2}$ bem como a pressão necessária para a inertização, instalação dos sensores, válvulas, filtro e outros componentes, podem ser estudadas em conjunto com a engenharia de manuteção. 


\section{CONCLUSÃo}

O objetivo deste artigo foi propor uma estratégia de manutenção e um conjunto de melhorias para aumento da disponibilidade em um posto de compressão de gases residuais do processo de destilação do petróleo, composto por dois compressores alternativos $A$ e $B$ em uma refinaria da indústria petrolífera. $A$ estratégia proposta foi a manutenção corretiva, ou seja, dado que uma falha ocorreu, não é feito apenas o reparo, mas tomadas medidas corretivas que sanem a deficiência. Tal estratégia se justifica pelo fato de o objeto se encontrar em mortalidade infantil, o que denota a existência de erros de projeto ou de definições inadequadas para o atual serviço. Estas inadequações devem ser sanadas para aumentar a disponibilidade do posto de compressão. Como o serviço mudou, devido à mudança da matéria-prima, a fase de mortalidade infantil era esperada. Os dados que foram empregados se originaram do histórico gerenciado pela Engenharia de Manutenção da empresa, o que destaca a importância dos registros e da qualidade das informações para análise estratégica.

A questão de pesquisa deste artigo foi: como aumentar a disponibilidade do posto de compressão? A resposta foi dada no capítulo 5 , com uma lista de melhorias que neutralizam ou ao menos amenizam as falhas estratificadas que foram observadas no posto de compressão. As ações ora propostas são de baixo impacto quanto a alterações de projeto e investimentos, e podem possibilitar o acompanhamento preditivo e aumentar a disponibilidade do posto de compressão, visto que a máquina reserva ficará condicionada e pronta para a partida sempre que a outra máquina necessitar intervenção. As modificações e instrumentação das máquinas podem ser implementadas pelo pessoal de operação e manutenção da planta, conjuntamente com os fabricantes.

Como continuidade de pesquisa, sugerem-se mais estudos em equipamentos petrolíferos de grande porte e uso de simulação computacional para a avaliação técnica das soluções propostas. Tal método é viável, haja vista que existem estratificações e contabilizações dos modos de falha, o que permite que se saiba em adianto o quanto se pode esperar de cada solução, segundo a eficiência de sua implantação. Também sugerem-se estudos em indústrias cuja competição seja baseada em aspectos tecnológicos e de prestação de serviços, tais como as indústrias descritas em Borchardt et al. (2010) e em Borchardt et al. (2008). 


\section{AGRADECIMENTOS}

Parte da pesquisa foi financiada pelo CNPq.

\section{REFERÊNCIAS}

BACKLUND, F.; AKERSTEN, P. RCM introduction: process and requirements management aspects. Journal of Quality in Maintenance Management, v.9, n.3, p.250-264, 2003. http://dx.doi.org/10.1108/13552510310493701

BARROS, J.; LIMA, G. A Gestão da manutenção no plano estratégico dos empreendimentos industriais. In: Anais do VII CNEG, CONGRESSO NACIONAL DE EXCELÊNCIA EM GESTÃO, 2011, Rio de Janeiro: 2011.

BLANCHARD, B.; VERNA, D.; PETERSON, E. Maintainability a Key to Effective Serviceability and Maintenance Management. New York: Wiley Interscience, 1995.

BLOCH, H.; HOEFNER, J. Reciprocating Compressors: Operation and Maintenance. Houston: Gulf Professional Publishing, 1996.

BORCHARDT, M.; SELLITTO, M.; PEREIRA, G. Serviços de pós-venda para produtos fabricados em base tecnológica. Produção Online, v.8, n.2, p.1-26, 2008.

http://dx.doi.org/10.14488/1676-1901.v8i2.121

BORCHARDT, M.; SELLITTO, M.; PEREIRA, G. Sistemas Produto-Serviço: referencial teórico e direções para futuras pesquisas. Produção Online, v.10, n.4, p.837-860, 2010. http://dx.doi.org/10.14488/1676-1901.v10i4.510

BRAND, G. Método de apoio à formulação de estratégia de manutenção em ambiente industrial: um estudo de caso. Dissertação de Mestrado, Universidade do Vale do Rio dos Sinos, Engenharia de Produção e Sistemas, São Leopoldo: 2011.

DODSON, B.; NOLAN, D. Reability Engineering Handbook. New York: Marcel Dekker, 2002.

FLEMING, P. Implementando a MCC em um Ambiente de TPM. Anais do III Seminário Brasileiro de Confiabilidade na Manutenção, v.1, p.76-86, 2000, São Paulo: ABRAMAN, 2000.

FOGLIATTO, F.; RIBEIRO, J. Confiabilidade e Manutenção Industrial. Rio de Janeiro: Elsevier, 2009.

FURMANN, J. Desenvolvimento de um Modelo para a Melhoria do Processo de Manutenção Mediante a Análise de Desempenho de Equipamentos. Florianópolis, 2002. Dissertação (Mestrado em Engenharia de Produção), Universidade Federal de Santa Catarina.

GROSH, D. A primer of reliability theory. New York: John Wiley \& Sons, 1989.

GUZZON, S. Proposta de análise quantitativa de confiabilidade a partir de dados qualitativos provenientes da FMEA. Dissertação de Mestrado. Engenharia de Produção, Universidade Federal do Rio Grande do Sul, Porto Alegre: 2009. 
KARDEC, A.; NASCIF, J. Manutenção Função Estratégica. Rio de Janeiro: Qualitymark: Petrobrás, 2001.

LAFRAIA, J. Manual de Confiabilidade, Mantenabilidade e Disponibilidade. Rio de Janeiro: Qualitymark, 2001.

LEÃO, S.; SANTOS, M. Aplicação da troca rápida de ferramentas (TRF) em intervenções de manutenção preventiva. Produção Online, v.9, n.1, p.1-26, 2009.

http://dx.doi.org/10.14488/1676-1901.v9i1.205

LIANG, W.; PANG, L.; ZHANG, L.; HU, J. Reliability-centered maintenance study on key parts of reciprocating compressor. Proceedings of the International Conference on Quality, Reliability, Risk, Maintenance, and Safety Engineering - ICQR2MSE, v.1, 15-18 junho, 2012, p.414-418, Chengdu: 2012.

http://dx.doi.org/10.1109/icqr2mse.2012.6246265

LIMA, R.; MOREIRA, R.; BAPTISTA, I.; GUEDES, F.; MATTOS, O. Avaliação da Formação de Filmes de FeS no Aço Carbono Exposto em Meios de $\mathrm{CO}_{2}$ e $\mathrm{H}_{2} \mathrm{~S}$ por Espectroscopia de Impedância Eletroquímica. Anais do Painel de Engenharia Mecânica e Metalúrgica PEMM 2011, 10-11 novembro de 2011, COPPE/UFRJ, Rio de Janeiro: 2011.

MAINIER, F.; VIOLA, E. O Sulfeto de Hidrogênio $\left(\mathrm{H}_{2} \mathrm{~S}\right)$ e o Meio Ambiente. Anais do II Simpósio de Excelência em Gestão e Tecnologia - SEGeT, 2005, v.2, p.612-618, Rio de Janeiro: 2005.

MARCORIN, W.; LIMA, C. Análise dos Custos de Manutenção e de Não-manutenção de Equipamentos Produtivos. Revista de Ciência \& Tecnologia, v.11, n.22, p.35-42, 2003.

MENDES, A. Manutenção Centrada em Confiabilidade: uma abordagem quantitativa. 2011. 85 f. Dissertação (Mestrado em Engenharia de Produção) -- Programa de PósGraduação em Engenharia de Produção, Universidade Federal do Rio Grande do Sul, Porto Alegre, RS, 2011.

MENGUE, D.; SELLITTO, M. Estratégia de manutenção baseada em funções de confiabilidade para uma bomba centrífuga petrolífera. Produção Online, v.13, n.2, p.759783, 2013. http://dx.doi.org/10.14488/1676-1901.v13i2.1341

MORABITO, R.; PUREZA, V. Modelagem e simulação. In: MIGUEL, P. (org.) Metodologia de Pesquisa em Engenharia de Produção e Gestão de Operações. Rio de Janeiro: Campus, 2010.

MOUBRAY, J. Introdução à manutenção centrada na confiabilidade. São Paulo: Aladon, 1996.

PROCONF2000. Confiabilidade de componentes. Software ProConf 2000. Copyright(C, Maxxi Gestão Empresarial, Porto Alegre, 2000.

RAMOS FILHO, J.; ATAMANCZUK, M.; MARÇAL, R. Seleção de técnicas de manutenção para processo de armazenagem pelo Método de Análise Hierárquica. Produção Online, v.10, n.1, p.142-166, 2010. http://dx.doi.org/10.14488/1676-1901.v10i1.375

RAPOSO, C. Overall Equipment Effectiveness: aplicação em uma empresa do setor de bebidas do polo industrial de Manaus. Produção Online, v.11, n.3, p.648-667, 2010. http://dx.doi.org/10.14488/1676-1901.v11i3.529 
RAUSAND, M.; HOYLAND, A. System reliability theory: models, statistical methods and applications. N. York: Wiley, 2004.

SANTOS, I. Metodologia para implementação de um programa de manutenibilidade no ciclo de vida de um sistema nuclear. Produção Online, v.6, n.3, p.1-28, 2006.

http://dx.doi.org/10.14488/1676-1901.v6i3.629

SELLITTO, M. Análise estratégica da manutenção de uma linha de fabricação metalmecânica baseada em cálculos de confiabilidade de equipamentos, GEPROS, v.2, n.1, p.97-108, 2007.

SELLITTO, M. Formulação estratégica da manutenção industrial com base na confiabilidade dos equipamentos. Produção, v.15, n.1, p. 44-059, 2005. http://dx.doi.org/10.1590/S0103$\underline{65132005000100005}$

SELLITTO, M. Inteligência artificial: uma aplicação em uma indústria de processo contínuo.

Gestão \& Produção, v.9, n.3, p.363-376, 2002. http://dx.doi.org/10.1590/S0104$\underline{530 \times 2002000300010}$

SELLITTO, M.; BORCHADT, M.; ARAÚJO, D. Manutenção centrada em confiabilidade: uma abordagem quantitativa. Anais do XXIIo ENEGEP. Curitiba: ABEPRO, 2002.

SIMÕES, J.; GOMES, C.; YASIN, M. A literature review of maintenance performance measurement: A conceptual framework and directions for future research. Journal of Quality in Maintenance Engineering, v.17, n.2, p.116-137, 2011.

http://dx.doi.org/10.1108/13552511111134565

SLACK, N.; CHAMBERS, S.; JOHNSTON, R. Administração da Produção. São Paulo: Atlas, 2002.

TAVARES, L. Excelência na Manutenção: Estratégias, Otimização e Gerenciamento. Salvador: Casa da Qualidade, 1996.

TSANG, A. Strategic dimensions of maintenance management. Journal of Quality in Maintenance Engineering, v.8, n.1, p.7-39, 2002.

http://dx.doi.org/10.1108/13552510210420577

WUTTKE, R.; SELLITTO, M. Cálculo da disponibilidade e da posição na curva da banheira de uma válvula de processo petroquímico. Produção Online, v.8, n.4, p.1-23, 2008. http://dx.doi.org/10.14488/1676-1901.v8i4.134

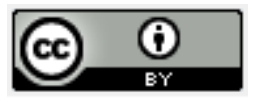

Artigo recebido em 01/11/2014 e aceito para publicação em 17/06/2015

DOI: http://dx.doi.org/ 10.14488/1676-1901.v16i1.1905 